\title{
Community-acquired pneumonia and acid-suppressive drugs: Position statement
}

\author{
CAG Clinical Affairs Committee
}

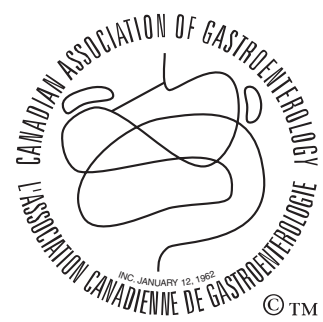

En français voir page 123

$\mathrm{R}$ ecently, considerable attention in the medical literature and lay press has been paid to the unrecognized side effects of widely used medications (1). With increasing evidence supporting a causative association between cyclooxygenase- 2 antiinflammatory drugs and cardiovascular events, the medical community and public in general appear to be taking a more conservative approach to pharmaceutical use $(2,3)$. However, it is not always clear that suggestions of potential risk are weighed against proven benefits. In this light, a recent article published in the Journal of the American Medical Association has suggested a link between the use of agents that suppress gastric acid production and community-acquired pneumonia (CAP) (4).

Acid-suppressive drugs (ASDs), particularly proton pump inhibitors (PPIs), are highly effective agents for the treatment and prophylaxis of many serious gastrointestinal diseases. Almost 40 years ago, histamine- 2 receptor antagonists $\left(\mathrm{H}_{2} \mathrm{RAs}\right)$ revolutionized the therapy of acid-related diseases. Over the past two decades, their place in the management and even prevention of serious conditions, such as gastroesophageal reflux disease (5) and peptic ulcer disease (6), has been superceded by the more potent PPI class.

Countless randomized controlled trials (RCTs) and years of clinical experience have clearly demonstrated that ASDs and particularly PPIs improve patient quality of life and heal serious mucosal disease $(7,8)$. For example, PPIs are the only agents to have been shown to reliably heal ulcerative esophagitis due to gastroesophageal reflux disease and maintain longterm healing (5). They are also a vital component of the most common Helicobacter pylori eradication regimens (9) and are convenient and effective agents for the treatment of prevention of ulcers caused by nonsteroidal anti-inflammatory drugs (10). PPIs, administered either via the intravenous or oral route, are integral to the treatment of upper gastrointestinal bleeding secondary to peptic ulcer disease (11), a condition with an underappreciated case fatality rate of up to $10 \%$ (12).

To date, ASDs have had a remarkable safety record. Initial concerns about the potential for complications ranging from vitamin malabsorption to gastric neoplasia have not been realized (13). There exists laboratory and clinical evidence to suggest that a less acidic gastric $\mathrm{pH}$ may be linked to increased bacterial colonization of the stomach (14). Studies up until recently looking specifically at clinical outcomes such as ventilator associated pneumonia in the critical care setting have not been definitive in either demonstrating or entirely refuting a link with ASDs $(15,16)$.

Although there are numerous placebo-controlled RCTs in the literature designed to explore the effectiveness of PPIs in acid-related disease, only a minority have reported pneumonia as a primary clinical outcome. Reviewing 60 such studies published over the last 13 years, only seven studies (17-23) have reported on 'respiratory infection' as a secondary outcome. A review of these studies by the Canadian Association of Gastroenterology shows that three of seven have reported a numerically higher incidence of respiratory infection in the group receiving PPIs, while in the other four the incidence was higher in the placebo group. The total number of patients in the seven studies was 2271 with an overall incidence of respiratory infection of $4.3 \%$ in the group receiving PPIs and $4.9 \%$ in the group receiving placebo. Although far short of a formal meta-analysis, the data available until recently thus do not appear to have demonstrated a link between ASDs and pneumonia, at least in the ambulatory patient population.

In contrast, recent exploratory data from Holland $(4,24)$ have suggested a possible association between ASD therapy and CAP. Until publication of these data, the predominance of the literature had focused on the role of ASDs in reducing reflux and, therefore, decreasing the potential for aspiration that could lead to chronic cough or reactive airways disease (25). The more recent study, using both a retrospective cohort and case control design, was conducted to explore the hypothesis that ASD therapy could cause pneumonia by increasing gastric bacteria colonization (4). These bacteria could then potentially travel to the lungs via the upper digestive and upper respiratory tracts. Studying almost one million patient years of data in the cohort, the authors found an unadjusted risk of 2.5 and 2.3 cases of CAP per 100 patient years in PPI and $\mathrm{H}_{2} \mathrm{RA}$ users, respectively, compared with 0.6 cases in

The CAG is proud to acknowledge its Benefactor Corporate Sponsors:

Abbott Laboratories Ltd Janssen-Ortho Inc

\author{
ALTANA Pharma Inc
}

Pfizer Canada Inc
AstraZeneca Canada Inc

Procter \& Gamble Pharmaceuticals
Axcan Pharma Inc

Schering Canada Inc 
nonusers, for an unadjusted RR of approximately 4.5. The author designed a case control analysis to attempt to control for the obvious confounder of clinical conditions requiring ASDs. Under the assumption that previous ASD users and current ASD users are similar, they took a group of ASD users who had acquired pneumonia (and 10 controls without CAP for each) and compared whether CAP occurred coincidently with or after ASD use. Using this less confounded design, the risk of CAP was reduced, with a statistically significant adjusted OR of 1.89 for PPIs and 1.63 for $\mathrm{H}_{2} \mathrm{RAs}$ when one compared persons diagnosed with CAP at the time of ASD use, with a group of patients diagnosed more than 30 days after their discontinuation. This translated into an attributable risk for ASD therapy of approximately one case of CAP per 100 years of ASD use.

Although a well performed study, the validity of the data appears to hinge primarily on the similarity of the two primary groups in the case control analysis - current and past ASD users that may not be comparable in many regards. A true RCT design would be optimal to address this question but would be difficult to conduct because of the need for a large sample size, a somewhat heterogenous outcome measure that could be influenced by diagnostic suspicion bias and perhaps because of a lack of an upside for any pharmaceutical sponsor. Without further data, it would be premature to allow this study to heavily influence prescribing practices. The risk to benefit ratio appears to be largely in favour of using ASDs for conditions in which efficacy has been demonstrated.

Only evidence-based and appropriate use of ASDs should be encouraged, as highlighted in another position statement by the Canadian Association of Gastroenterology on a possible relationship between PPI use and Clostridium difficile infection (26). Use considerations include not only drug therapy initiation, but also the length of time that therapy should be continued and the dosage prescribed. Most studies of PPIs have been designed to demonstrate benefit over a relatively short defined period, usually measured in months, whereas in clinical practice many patients may be prescribed these medications for indefinite periods, not uncommonly measured in years.

The risks and benefits of initiating and continuing ASD therapy need to be considered on a case by case basis. The Canadian Association of Gastroenterology encourages its members and indeed all health professionals to keep abreast of any additional publications of relevant data.

ACKNOWLEDGEMENT: The CAG would like to thank the sponsors, AstraZeneca Canada Inc, Ferring Pharmaceuticals, Janssen-Ortho Inc, McNeil Consumer Healthcare and Rivex Pharma Inc for their support. Unrestricted funding was provided to the CAG for the annual Clinical Affairs Meeting, which in part, was dedicated to the development of this position paper.

CLINICAL AFFAIRS COMMITTEE MEMBERS: Alan Barkun (AB) - Chair, CAG Clinical Affairs Committee; Robert Enns (RE) - Chair, CAG Endoscopy Committee; Cameron Ghent (CG) - Chair, CAG Hepatobiliary Committee; Peter Lightfoot (PL) - Chair, CAG Regional Representation Committee; Margaret Marcon (MM) - Chair, CAG Pediatric Committee; Susan Natsheh (SN) - Chair, CAG Liaison Committee; Daniel Sadowski (DS) - Chair, CAG Practice Affairs Committee. Sponsor Observers: Olana Alcock - Ferring Pharmaceuticals; John Hands - McNeil Consumers Healthcare.

DISCLOSURE BY THE CAG CLINICAL AFFAIRS COMMITTEE: No, I (or my spouse/partner) have not received financial support from any industrial sponsor: (MM, PL, SN). Yes, I have received consultant fees: Altana (RE), AstraZeneca (RE, DS), Janssen (RE), Roche (CG), Schering (RE). Yes, I have received research grants: Altana $(A B, R E)$, AstraZeneca (AB,RE), Axcan (RE). Yes, I have received clinical trial funding: Abbott (DS), Altana (RE), AstraZeneca (RE), Berlex (RE), Elan (RE), Osuka (RE), Novartis (DS), Roche(RE), Solvay (DS). Yes, I have participated in speaker's bureaus: Abbott (DS), Altana (AB, RE), AstraZeneca (AB, RE), Janssen (RE), Novartis (RE, DS), Procter \& Gamble (RE), Roche (CG), Schering (RE, CG), Orthobiotec (CG).

\section{REFERENCES}

1. Okie S. What ails the FDA? N Engl J Med 2005;352:1063-6. (Erratum in 2005;352:2563).

2. Drazen JM. COX-2 inhibitors - a lesson in unexpected problems. N Engl J Med 2005;352:1131-2.

3. Psaty BM, Furberg CD. COX-2 inhibitors - lessons in drug safety. N Engl J Med 2005;352:1133-5.

4. Laheij RJ, Sturkenboom MC, Hassing RJ, Dieleman J, Stricker BH, Jansen JB. Risk of community-acquired pneumonia and use of gastric acid-suppressive drugs. JAMA 2004;292:1955-60.

5. Chiba N, De Gara CJ, Wilkinson JM, Hunt RH. Speed of healing and symptom relief in grade II to IV gastroesophageal reflux disease: A meta-analysis. Gastroenterology 1997;112:1798-810.

6. Valenzuela JE, Berlin RG, Snape WJ, et al. US experience with omeprazole in duodenal ulcer. Multicenter double-blind comparative study with ranitidine. The omeprazole DU comparative study group. Dig Dis Sci 1991;36:761-8.

7. Rampal P, Martin C, Marquis P, Ware JE, Bonfils S. A quality of life study in five hundred and eighty-one duodenal ulcer patients. Maintenance versus intermittent treatment with nizatidine. Scand J Gastroenterol Suppl 1994;206:44-51.

8. Pare P, Armstrong D, Pericak D, Pyzyk M. Pantoprazole rapidly improves health-related quality of life in patients with heartburn: A prospective, randomized, double blind comparative study with nizatidine. Clin Gastroenterol 2003;37:132-8.

9. Ford A, Delaney B, Forman D, Moayyedi P. Eradication therapy for

peptic ulcer disease in Helicobacter pylori positive patients. Cochrane Database Syst Rev 2004;4:CD003840.

10. Rostom A, Dube C, Wells G, et al. Prevention of NSAID-induced gastroduodenal ulcers. Cochrane Database Syst Rev 2002;4:CD002296.

11. Leontiadis GI, McIntyre L, Sharma VK, Howden CW. Proton pump inhibitor treatment for acute peptic ulcer bleeding. Cochrane Database Syst Rev 2004;3:CD002094.

12. Barkun A, Sabbah S, Enns R, et al. The Canadian Registry on Nonvariceal Upper Gastrointestinal Bleeding and Endoscopy (RUGBE): Endoscopic hemostasis and proton pump inhibition are associated with improved outcomes in a real-life setting. Am J Gastroenterol 2004;99:1238-46.

13. Laine L, Ahnen D, McClain C, Solcia E, Walsh JH. Review article: Potential gastrointestinal effects of long-term acid suppression with proton pump inhibitors. Aliment Pharmacol Ther 2000;14:651-68.

14. Theisen J, Nehra D, Citron D, et al. Suppression of gastric acid secretion in patients with gastroesophageal reflux disease results in gastric bacterial overgrowth and deconjugation of bile acids. J Gastrointest Surg 2000;4:50-4.

15. Cook D, Guyatt G, Marshall J, et al. A comparison of sucralfate and ranitidine for the prevention of upper gastrointestinal bleeding in patients requiring mechanical ventilation. Canadian Critical Care Trials Group. N Engl J Med 1998;338:791-7. 
16. Mallow S, Rebuck JA, Osler T, Ahern J, Healey MA, Rogers FB. Do proton pump inhibitors increase the incidence of nosocomial pneumonia and related infectious complications when compared with histamine- 2 receptor antagonists in critically ill trauma patients? Curr Surg 2004;61:452-8.

17. Talley NJ, Lauritsen K, Tunturi-Hihnala $\mathrm{H}$, et al. Esomeprazole 20 mg maintains symptom control in endoscopy-negative gastrooesophageal reflux disease: A controlled trial of 'on-demand' therapy for 6 months. Aliment Pharmacol Ther 2001;15:347-54.

18. Vakil NB, Shaker R, Johnson DA, et al. The new proton pump inhibitor esomeprazole is effective as a maintenance therapy in GERD patients with healed erosive oesophagitis: A 6-month, randomized, double-blind, placebo-controlled study of efficacy and safety. Aliment Pharmacol Ther 2001;15:927-35.

19. Miner P Jr, Orr W, Filippone J, Jokubaitis L, Sloan S. Rabeprazole in nonerosive gastroesophageal reflux disease: A randomized placebo-controlled trial. Am J Gastroenterol 2002;97:1332-9.

20. Johnson DA, Benjamin SB, Vakil NB, et al. Esomeprazole once daily for 6 months is effective therapy for maintaining healed erosive esophagitis and for controlling gastroesophageal reflux disease symptoms: A randomized, double-blind, placebo-controlled study of efficacy and safety. Am J Gastroenterol 2001;96:27-34. (Erratum in 2001;96:942)

21. Richter JE, Bochenek W. Oral pantoprazole for eroxive esophagitis: A placebo-controlled, randomized clinical trial. Am J Gastroenterol 2000;95:3071-80.

22. Valenzuela JE, Kogug DG, McCullough AJ, et al. Comparison of once-daily doses of omeprazole (40 and $20 \mathrm{mg}$ ) and placebo in the treatment of benign gastric ulcer: A multicenter, randomized, double-blind study. Am J Gastroenterol 1996;91:2516-22.

23. Sontag SJ, Hirschowitz BI, Holt S, et al. Two doses of omeprazole versus placebo in symptomatic erosive esophagitis: The US multicenter study. Gastroenterology 1992;102:109-18.

24. Laheij RJ, Van Ijzendoorn MC, Janssen MJ, Jansen JB. Gastric acidsuppressive therapy and community-acquired respiratory infections. Aliment Pharmacol Ther 2003;18:847-51.

25. Kiljander TO. The role of proton pump inhibitors in the management of gastroesophageal reflux disease-related asthma and chronic cough. Am J Med 2003;115:65S-71S.

26. Canadian Association of Gastroenterology, Clinical Affairs. Clostridium difficile-associated diarrhea (CDAD) and proton pump inhibitor therapy: CAG Position Statement. Can J Gastroenterol 2005;19:373-5. 


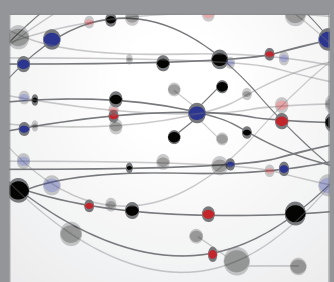

The Scientific World Journal
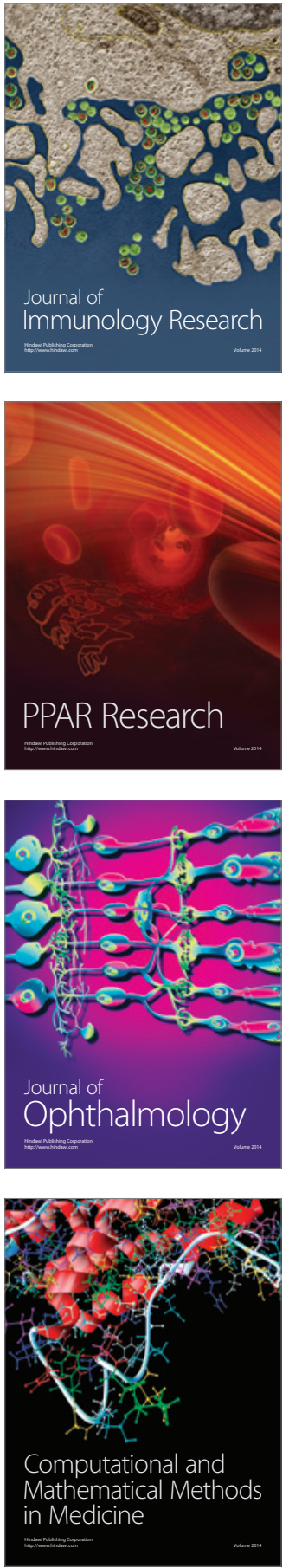

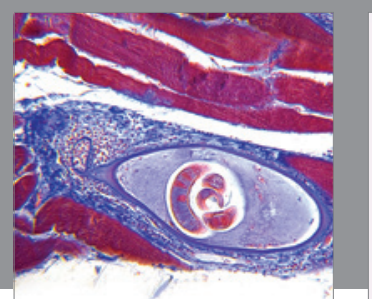

Gastroenterology Research and Practice

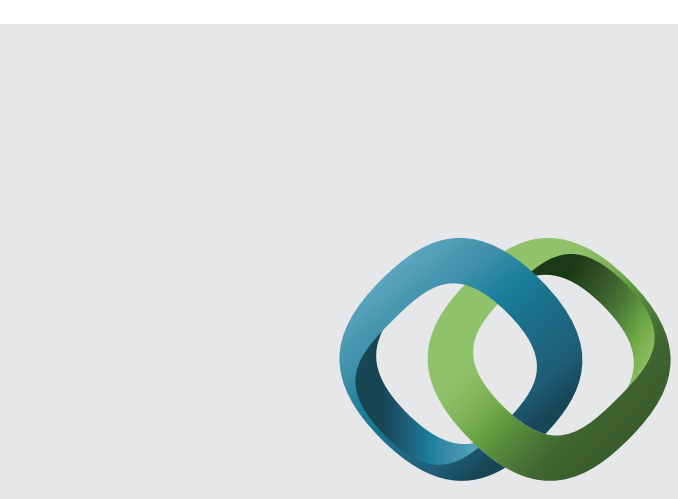

\section{Hindawi}

Submit your manuscripts at

http://www.hindawi.com
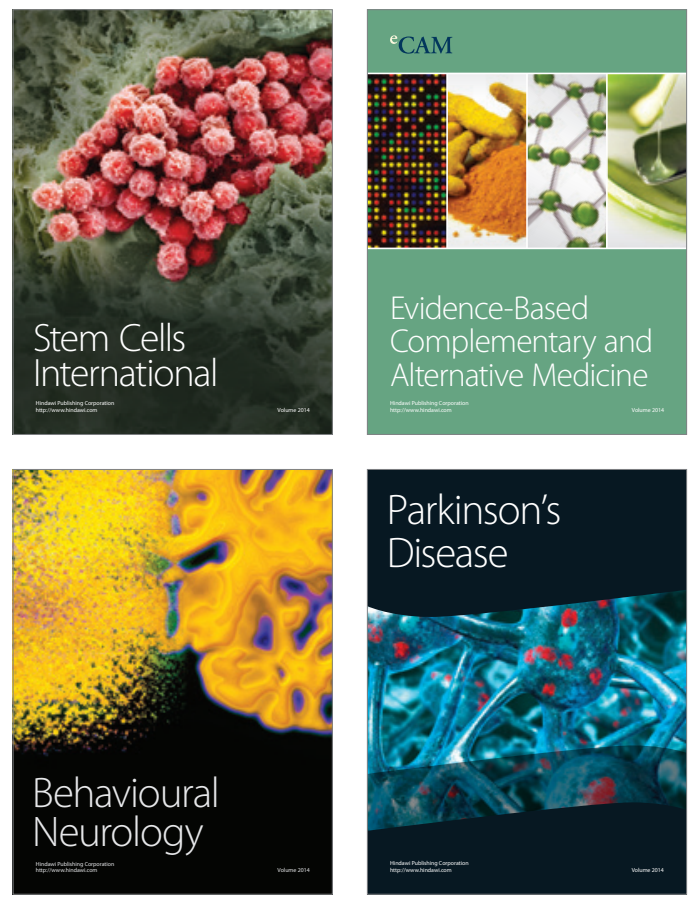
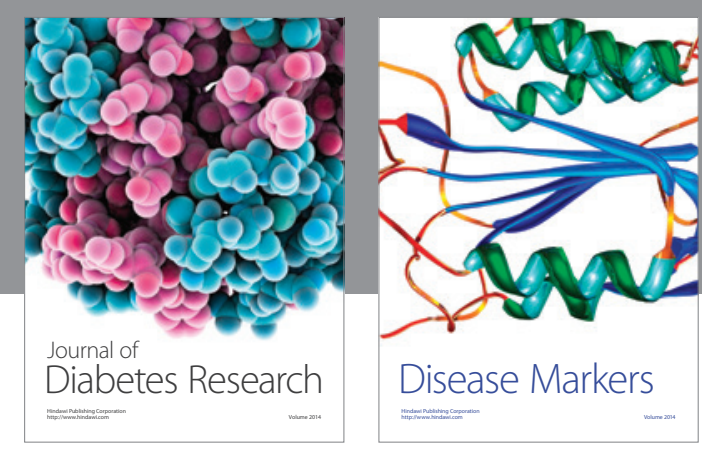

Disease Markers
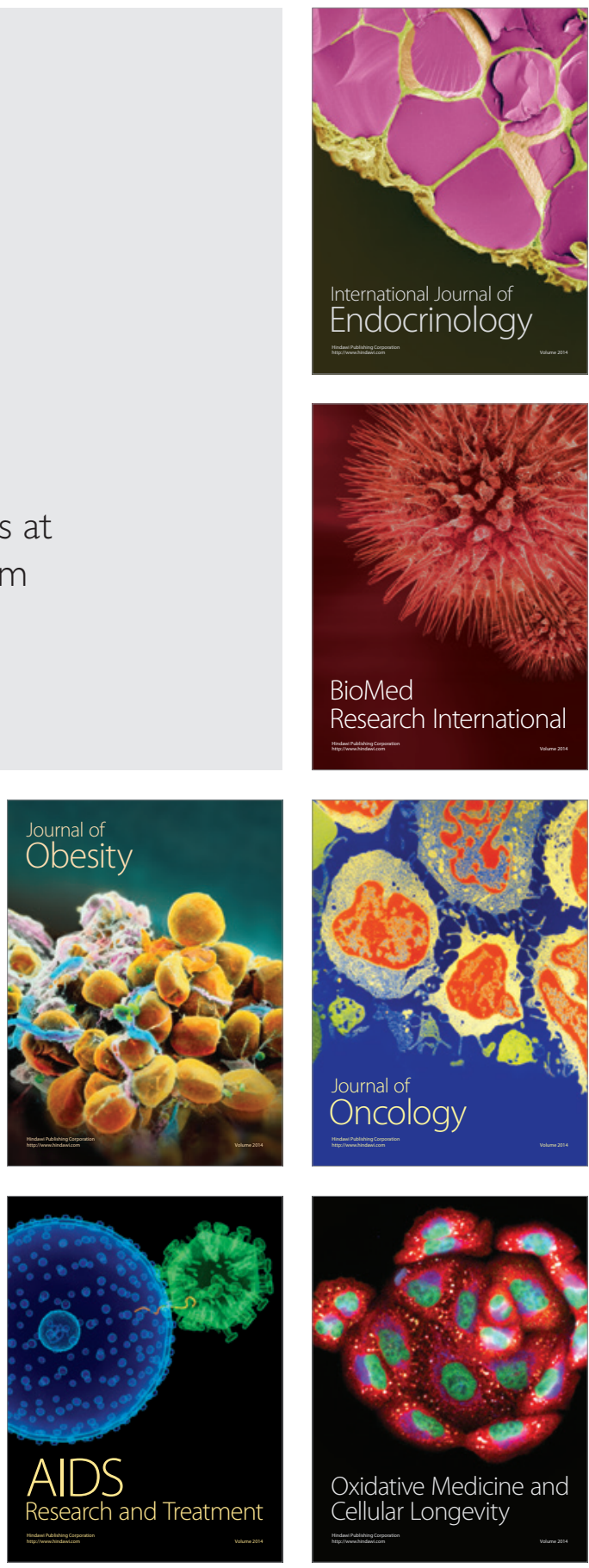